\title{
BASE ISOLATION FOR INCREASED EARTHQUAKE RESISTANCE OF BUILDINGS
}

\author{
R. I. Skinner* and G. H. McVerry*
}

\section{ABSTRACT}

Inelastic deformation and hysteretic damping increase the earthquake resistance of structures beyond that provided by their elastic strength. For many structures the reserve flexibility and the damping could be supplied efficiently and reliably. by the use of special components.

Special components are most effective when they are located at the interface between the lowest part of the building and the foundations. Recently developed hysteretic dampers, utilizing the plastic deformation of solid steel bars, may be combined with one of the many methods suggested for achieving base flexibility to give a practical and efficient base-isolation system.

In addition to reducing the general level of attack a baseisolation system greatly reduces the variation in severity of attack resulting from differences in character between earthquakes. In view of the range of earthquake types to which a structure may be subjected this "standardization" of the earthquake attack is important, and is found to be particularly important for structures with a fundamental period of less than 0.4 seconds.

A base-isolation system reduces ductility demands on a building, and minimizes its deformations. These changes improve building performance and allow much greater architectural freedom in the choice of the structural type and in its layout and detailing. Economies are increased and performance improved by using highstrength low-ductility structural configurations.

\section{INTRODUCTION}

During an earthquake the principal attack on a structure is by transient horizontal forces. The earthquake resistance of the structure depends on a combination of elastic strength, inelastic deformability and damping capacity. The relative effectiveness of these three factors depends in part on the character of the attacking earthquake.

Typical earthquakes have one of four characteristics ${ }^{1}$ :

Type 1 earthquakes are impulsive with a single dominant lurch in one direction. Structures may resist these earthquakes by a combination of elastic strength and inelastic deformability; damping adds little to their resistance.

Type 2 earthquakes are of long duration with irregular "noise-like" ground motions. Structures resist them by elastic strength, inelastic deformability, and by damping which reduces the cyclic buildup of deformations.

Type 3 earthquakes are of long duration and have regular motions with one or more dominant periods. They are a consequent of the partial resonance of flexible ground and are therefore a microzone effect. Damping makes an important contribution to the earthquake resistance of any structure which

* Engineering Seismology Section, Physics and Engineering Laboratory, Department of Scientific and Industrial Research, New Zealand. has a fundamental period similar to a dominant period of the earthquake. Avoidance of such near-coincidence of periods may be impeded by architectural requirements, by difficulty in predicting earthquake periods, and by increases in ground period with increasing ground strains.

Type 4 earthquakes are those which include severe ground damage in addition to the inertia attack, and this poses special design problems which are not considered in this paper.

Economy of design is achieved by allowing a structure to deform well into the inelastic range during severe earthquakes. Effective earthquake resistance may be obtained provided the structure has adequate capacity for inelastic deformation and for associated hysteretic damping.

The capacity of a structure to deform inelastically is expressed as a ductility factor, defined as the ratio of 'the maximum deflection which can be sustained for several cycles' to 'the deflection at initial yield'. The ductility demand on a structure with a fundamental period of more than 0.4 seconds is given approximately by the ratio of 'the load which would arise if the structure remained elastic' (given for example by the dotted spectra of Fig.1) to 'the load at which initial yield occurs'. However for short-period structures the ductility demand may greatly exceed this load ratio, as shown in Fig. 4, where $\mathrm{P}_{\mathrm{a}}$ and $P_{p}$ give amplitude and period scaling of the accelerations recorded at El Centro, 
1940, N S component, a typical type 2 earthquake.

Increasingly sophisticated techniques have been adopted to increase the capacity of structural members for inelastic deformation and hysteretic damping. The ductility of reinforced concrete can be increased by appropriate detailing of the reinforcing steel but it still suffers progressive deterioration under successive cycles of severe inelastic deformation, while structural steel members may suffer progressive damage and loss of strength due to local buckling. Moreover the post-elastic deformations of flexible building frames may result in expensive secondary damage. Thus attempts to provide resistance to severe earthquakes by providing a high ductility factor have introduced considerable uncertainty to the assessment of structural performance.

Furthermore recent calculations show that ductility demands on short-period buildings, designed for moderate yield levels, may be particularly severe. Hence special devices which provide high ductility in a reliable manner will reduce the uncertainty in earthquake-resistant design.

\section{SPECIAL COMPONENTS TO INCREASE EARTHQUAKE RESISTANCE}

Other groups have developed special components to increase the earthquake resistance of buildings with flexible frames. The components act as stiffening braces during moderate deformations and as hysteretic dampers during large deformations. Slitwall reinforced-concrete panels have been installed over the height of a number of tall buildings in Japan. Another system considered employs a set of steel structural beams arranged diagonally to concentrate most of the interstorey deflections in short lengths of structural steel beam, an example of which is the "Y-brace". Since the special components for bracing and hysteretic damping have been relieved of the normal building loads they may be optimized for their bracing and damping functions. They reduce the ductility demands on the main structural frame and reduce the interstorey deformations. However both the slit walls and the steel beam brace systems are liable to deterioration under severe cyclic deformations.

Bracing and damping components constitute a considerable part of a frame since they extend throughout the building and since they must provide forces comparable with the lateral resistance of the frame. They are essentially large-force small-deformation systems, and are appropriate for use with flexible building frames.

Base support systems which provide major structures with substantial isolation from earthquake attack are a practical possibility following development work on low-cost hysteretic dampers at the Engineering Seismology Section, PEL, DSIR, New Zealand 2,3 . These dampers are based on the hysteretic deformation of solid steel bars. They have the required damper force capacity and operating stroke; typically 5 to 50 tons and 8 inches respectively. A damper for operations along a single line of action is shown in Fig. 6. The outer arms are supported and the inner arms are loaded to cause severe inelastic deformations, primarily torsional, in the solid steel bar.

A damper suitable for operation in any horizontal direction is shown in Fig. 7. It utilizes a solid steel bar in the form of a short vertical cantilever. When the base of the cantilever is fixed to the foundations horizontal loads are applied to the top of the cantilever via a tube and spherical surface. An alternative damper employs two short cantilever bars in a stalagmitestalactite configuration, the adjacent ends being connected by a shear pin which allows axial extension. The base of one cantilever is fixed to the foundations, and the upper end of the other is fixed. to the lowest floor of the structure.

Hysteretic dampers based on the extrusion of lead have been developed recently 4,5 . These dampers can be designed to have a very large ratio of inelastic to elastic deformation, and therefore provide special isolator design possibilities.

Hysteretic dampers of the types described are characterized by a moderate operating force and a large stroke. Also they can be designed to operate for hundreds of cycles at well controlled force levels. Dampers with this set of characteristics are appropriate for use in a base-isolating system.

A further component required for a baseisolating system is one which supports the structure, allows relatively free horizontal motion, and provides a moderate centring force. For many structures the most convenient mount which has these characteristics is a laminated rubber bearing of the type frequently used to support bridge decks

\section{BASE ISOLATION OF STRUCTURES}

It has often been suggested that base isolation of buildings may be achieved by introducing base supports with large elastic flexibility for horizontal motions. While such isolators may operate satisfactorily during type 1 (impulsive) earthquakes they would allow the cyclic build-up of intolerable base translations, and of considerable loads on the building, during the longer type 2 and type 3 earthquakes. Moreover the buildings would be liable to frequent unacceptable movements during wind storms.

The recently developed hysteretic dampers 2,3 may be connected between the base and the foundations of a flexiblymounted structure to act as stiff braces during wind storms, and to provide damping and softening which limits the build-up of structural movements and forces during severe earthquakes 7 . The increased damping and increased effective period, due to the base isolator, are found to be particularly effective in reducing the earthquake attack on structures with a fundamental period of less than 1.0 second.

A base-isolated structure with a fundamental period of less than 1.0 second may be represented approximately by a single mass with a flexible support, for the purpose of computing its dynamic response to 
earthquake attack. This model is quite accurate for buildings with periods of less than 0.5 seconds. Since all the masses of a base-isolated building have comparable accelerations the deformed shape of the building is almost the same as for "uniform" horizontal loads, that is loads proportional to building weights. The total mass may then be taken at the centre of gravity of the building, and its support should allow it the same translations as the centre of gravity. This may be achieved by a support which gives an effective period of

$$
\mathrm{T}_{\mathrm{e}}=0.85 \mathrm{~T} \text {, }
$$

where $T$ is the fundamental period of the building. (The relationship may be derived from Raleigh's period formula when suitable approximations are made). The accuracy of the single-mass model is increased by large inelastic deformations of the isolator, and the model is not invalidated by moderate inelastic deformations of the building. When the maximum base shear has been obtained by dynamic analysis then the maximum member loads and the maximum deformations may be determined accurately by static calculation, with the base shearforce distributed uniformly over the building.

The choice of the flexibility of the base mounts and of the effective force of the hysteretic dampers depends on the sizes of the design earthquakes, and on the characteristics and installed costs of the base-isolator components. A suitable compromise between building protection and isolator costs may be achieved with flexible mounts of laminated rubber having an effective rubber height of 6 inches, and with steel-bar hysteretic dampers which provide an effective damper force of $5 \%$ of the building weight. Such laminated rubber mounts can be selected to give to a rigid building a period of 2.0 seconds, in the absence of the hysteretic dampers. Then from the period formula for a single-mass resonator it is found that the mount stiffness is $0.0255 \mathrm{~W}$ in -1 , where $\mathrm{W}$ is the weight of the building. The two stiffness values for the bilinear loop, which approximates the load-deflection curves of typical steel-beam dampers, designed for maximum deflections of 8 inches, are 2.940 in -1 and $0.18 Q$ in -1 , where $Q$ is the effective damper force. The results presented in this paper are based on isolators having the above features.

\section{RESPONSE OF BASE-ISOLATED STRUCTURES}

Fig.l presents the base shears computed for a single-mass model of a linear elastic building of period $T$, mounted on the isolator described in the last section and then subjected to $\mathrm{P}_{\mathrm{a}}$ times the accelerations recorded at El Centro, May 1940, N S component; a typical type 2 earthquake. In the following this record will be referred to as the El Centro earthquake. An overall viscous damping of 0.03 of critical was assumed for the building and the mounts. It is seen that for $\mathrm{P}_{a}=1.0$, 1.5 and 2.0, the maximum base shares are approximately $0.15 \mathrm{~W}, 0.20 \mathrm{~W}$, and $0.29 \mathrm{~W}$, respectively. The corresponding base translations, which may be derived from the loads required to deform the isolator, are 2.9 inches, 4.4 inches, and 7.0 inches, respectively. For comparison Fig.l also gives the corresponding base shares for non-isolated single-mass resonators with a viscous damping of 0.05 . As discussed below these curves do not adequately represent the severity of the attack on short-period buildings (less than 0.5 seconds).

It is evident from Fig.l that practical designs for buildings having an elastic response only will normally be confined to those with base isolation, when highstrength low-ductility types of structure may be employed such as exterior frames of deep beams and wide columns, shear walls, or frames with diagonal braces. Prestressed members, with their high strength and low damping, are appropriate for use in a base-isolated structure.

An attractive solution for a frame building which contains a few shear walls is the provision of support for the shear walls by vertical solid-steel bars, 3 to 4 feet in length, with the upper and lower ends of the bars rigidly anchored to a shear wall and to the foundations respectively. The columns of the frames are supported on laminated rubber mounts. For horizontal translation of the building the solid steel bars act as verticalcantilever dampers, and they also act as ties to prevent rocking of the walls due to building overturning moments. The transverse stiffness of the rubber mounts provides adequate resistance against the $p$ - $\Delta$ forces arising from translation of the short steel bars.

The ductility demands which arise when a yielding building of 0.35 seconds period is mounted on the base isolator are given in Fig.2. The load-deformation characteristics of the building were represented by bilinear hysteresis loops with slope ratios, $R$, which is the ratio of slope in the plastic range to slope in the elastic range, of $0.1,0.15$ and 0.2 . The ductility demands were computed for accelerations of 1.5 and 2.0 times those of the El Centro earthquake. It is seen that, for a building with a bilinear slope ratio of 0.15 , yield force levels of $0.13 \mathrm{~W}$ and $0.17 \mathrm{~W}$ restrict the ductility demand to 4.0 for earthquake amplitude multipliers of 1.5 and 2.0 respectively. The curves of Fig. 2 have been calculated specifically for a building elastic period of 0.35 seconds; however they should apply approximately to all short-period buildings.

It may be shown that the attack of a type 1, impulsive, earthquake on a baseisolated building is a little less severe than the attack of a type 2 earthquake of the same maximum ground velocity and acceleration.

It is evident from Fig.2 that the building bilinear slope ratio has an important influence on the ductility demands on a baseisolated building. While tests on reinforced concrete beam-column connections suggest a slope ratio of 0.1 or less for a reinforced concrete frame, tests on complete reinforced concrete buildings give much higher values when the ductility demands are moderate. This high slope ratio is presumably caused partly by progressive formation of member 
hinges and partly by the beam action of the floor slabs, which do not particpate fully in the hinging of associated beams. If a slope ratio of 0.1 may not be available the design should be modified to achieve it, or member yield levels set which will prevent the formation of a complete mechanism under design earthquakes.

Base isolation reduces the attack on short-period buildings to an even greater extent than is indicated by the low ductility demands of Fig.2. A shortperiod building, when base-isolated, has its period increased to about 0.7 seconds for moderate vibration amplitudes, and to effective periods of about 1.2 and 2.0 seconds respectively for earthquake accelerations of 1.0 and 2.0 times the accelerations of the El Centro earthquake. These overall periods are much longer than those of the short-period building alone and therefore the building responses are approximately the same as they would be if the inertia loads were applied statically. Hence an equivalent static design, with the dynamically calculated base shears distributed uniformly, gives accurate loads and deformations. Moreover there is no dynamic magnification of the statically computed effects of torsional unbalance, set-backs, and severe irregularities of structural form. Again the dominant periods of angular accelerations of the ground must be at least as short as the dominant periods of linear accelerations of the ground and therefore base isolators will prevent dynamic amplification of the associated torsional forces.

The severe resonant attacks which may occur on the appendages of non-isolated buildings are suppressed by base isolation. The effective building period is increased well beyond the dominant periods of most earthquakes, and the overall period is amplitude dependent and heavily damped during severe earthquakes. These three factors reduce the floor spectra and hence reduce the attack on building appendages.

Base isolation provides large reductions in the earthquake attack on short-period buildings, and it gives a structure which can be designed simply and accurately. Isolation may provide a considerable reduction in the attack on buildings with longer fundamental periods, say greater than 0.7 seconds, but the design of such isolated buildings is more complex as there may be more than one significant mode of vibration, and for slender buildings overturning effects may be important. A study of such buildings is now in progress.

\section{COMPARISON OF ISOLATED AND. NON-ISOLATED}

The earthquake attack on a building, with and without base isolation, may be compared on the basis of the overall ductility demand on the building. For analysis the short-period non-isolated buildings were approximated by a singlemass system with the building loaddeformation characteristics represented by a bilinear hysteretic loop with a slope ratio of 0.1 . The ductility demands for scaled El Centro earthquakes are given in Fig. 3. It is seen that the ductility demands are very high in short-period buildings with moderate yield levels. A check shows that these ductility demands are much higher than the ratio of the load for an elastic response to the load at yield; a load ratio which approximates ductility demand for buildings of period greater than about 0.4 seconds. The excess of the ductility demand over the ratio of the elastic to the yield load is given by Fig. 4. Similar severe ductility demands will arise when impulsive, type 1, earthquakes attack short-period buildings.

From Figs. 2 and 3 it is evident that base isolation gives a substantial reduction in the minimum yield level necessary for short-period buildings. For example, if the allowable ductility demand is 4 for twice the El Centro earthquake $\left(P_{=}=2\right)$ then the isolated building requires a base-shear yield force of $0.18 \mathrm{~W}$, while a non-isolated building, with a period between 0.1 and 0.35 seconds, requires a base-shear yield force of about $0.55 \mathrm{~W}$. Moreover since the base shear force is uniformly distributed over the masses of an isolated building, but has an inverted-triangle distribution for a non-isolated building, the total beam-end moments for non-isolation are $20 \%$ to $30 \%$ higher than for isolation when the base shear forces are the same.

Special problems arise when an attempt is made to design buildings for large ductility demands. These problems include the interaction between the normal building loads and the seismic loads, which may increase the rate of deterioration of severely plastic regions. Again the maximum member ductility may considerably exceed the mean member ductility. There may be an uncertain inter-action between different types of component, such as beams and the adjoining floor slabs. The irregularities of a building may be increased by unequal yield characteristics of balancing components, or by assymetric yield characteristics. When an assymetry of overall yield level occurs it may result in a systematic drift and hence in a large increase in ductility demand. These problems are avoided when base isolation is used since it ensures elastic response of a building, except during very severe earthquakes when only moderate ductility demands occur.

\section{DESIGN WITH BASE ISOLATION}

When checking the aseismic design of a base-isolated reinforced-concrete building a normal overcapacity factor of 1.25 times is assumed. If the design is controlled by beam-end moments it may still be desirable to proportion the members for an invertedtriangle distribution of loads despite the actual uniform distribution. This will give a further reserve of $20 \%$ to $30 \%$ and hence the overall reserve may be taken as $50 \%$. Further the provision for triangular loads will increase the effective bilinear stiffness ratio for moderate ductility factors.

Consider as an example a reinforced concrete building of 3 storeys with a fundamental period of 0.25 seconds, and with an overall viscous damping of 0.05 . If the design base shear is for a yield level of $0.12 \mathrm{~W}$, and if the members are designed for a 
triangular load distribution, then the elastic reserve may be taken as $50 \%$ and the effective base yield level as $0.18 \mathrm{~W}$. From Figs. 1 and 2 it is found that the building remains elastic until the ground accelerations reach 1.2 times those of the El Centro earthquake. For 1.5 and 2.0 times the El Centro earthquake the ductility demands are 1.5 and 3.7 respectively, assuming a bilinear stiffness ratio of 0.15 .

For comparison with the base-isolated building, the ductility demands are given for the building without base isolation, with a design base share of $0.16 \mathrm{~W}$, and with a viscous damping of 0.05 . For an overcapacity factor of 1.25 the yield load is $0.2 \mathrm{~W}$. The equivalent weight $\mathrm{W}_{e}$ of a singlemass system may be taken as 90 옹 of the building weight, so that the yield load is $0.22 \mathrm{~W}_{e}$. From Figs 1 and 4 it is found that the building reaches its yield level for accelerations of 0.25 times the $\mathrm{El}$ Centro earthquake and that the ductility demands for $1.0,1.5$ and 2.0 times the E.I Centro accelerations are $6.2,11.5$ and 18.5 respectively. The ratio of maximum member ductility to the above overall ductilities will be much higher and more variable for a range of earthquakes than the corresponding ratio for base-isolated buildings, for the reasons enumerated earlier.

The high ductility demands on the nonisolated building, when under severe earthquake attack, would lead rapidly to lower yield levels and to negative bilinear slope ratios which would further increase ductility demands and lead to rapid failure. The ductility demands for the isolated and the non-isolated buildings are given in Fig. 5. Since the dominant periods of earthquake motions tend to increase with earthquake magnitude the results of period increases of 1.25 and 1.5 , for earthquakes with amplitudes of 1.5 and 2.0 times the accelerations of the El Centro earthquake, are also included on Fig 5. While the largest earthquakes considered will occur very infrequently it is desirable that buildings should have a good probability of surviving them without collapse. If the base yield levels adopted above are used with buildings of periods less than 0.25 seconds, then with base isolation there are no increases in ductility demand, but without isolation there may be large increases.

If the two buildings of Fig. 5 have the same design load deformations then, for any given earthquake, the non-isolated building suffers more than 5 times the deformations of the isolated building. If the stiffer high-strength low-ductility forms appropriate to base isolation are adopted then even smaller building deformations will result. These small deformations should greatly reduce non-structural damage and the cost of providing for building deformations.

\section{CONCLUSION}

The design of short-period buildings is much more accurate and controlled with base isolation than without isolation. The long effective periods and high dampings "standardize" the earthquake attacks while base-isolation simplifies and "standardizes" the building response. The main inelastic components are a standard range of devices with reliable performance which can be thoroughly checked in the laboratory. The building loads are approximately static in their effects and their distribution is accurately defined. Hence the demands on the building components can be computed by straight-forward static techniques.

Base isolation suppresses several factors which act as severe constraints on the architectural design of a nonisolated building. These factors include the provision of a high overall ductility factor, the dynamic effects of irregularities and appendages, and provision for substantial building deformations.

Certain type 3 earthquakes can be expected to extend the very severe ductility demands, encountered in the analysis of short-period non-isolated buildings, to buildings of longer period. Base isolation should prove particularly effective in providing earthquake resistance for longerperiod buildings in microzones which give such type 3 earthquakes.

\section{REFERENCES}

1. Newmark, N.M. and Rosenblueth, E. : Fundamentals of Earthquake Engineering, Prentice-Hall 1971, pp. 225-228, and $343-345$.

2. Skinner, R.I., Kelly, J.M., and Heine, A.J., Hysteretic Dampers for EarthquakeResistant Structures, Int. J. Earthq. Engng struct. Dyn., Vol. 3, No.3, 1975 .

3. Skinner, R.I., Kelly, J.M., and Heine, A.J., Energy Absorption Devices for Earthquake Resistant Structures, Proc. 5 th Wld. Conf. Earthq. Engng, Session 8C, Rome, Italy (1973).

4. Robinson W.H. and Greenbank L.R., An Extrusion Energy Absorber Suitable for the protection of Structures During an Earthquake. In press - Int. J. Earthq. Engng Struct. Dyn. 1975.

5. Robinson W.H., Greenbank L.R., Properties of an Extrusion Energy Absorber. This Conference, May 1975.

6. Lindley, P.B., Engineering Design with Natural Rubber, N.R. Technical Bull., 3 rd edn, Natural Rubber Producers Research Association, London, 1970.

7. Skinner, R.I., Beck, J.L. and Bycroft, G.N., A Practical System for Isolating Structures from Earthquake Attack, Int. J. Earthq. Engng Struct. Dyn. Vol 3, No. 3, 1975. 


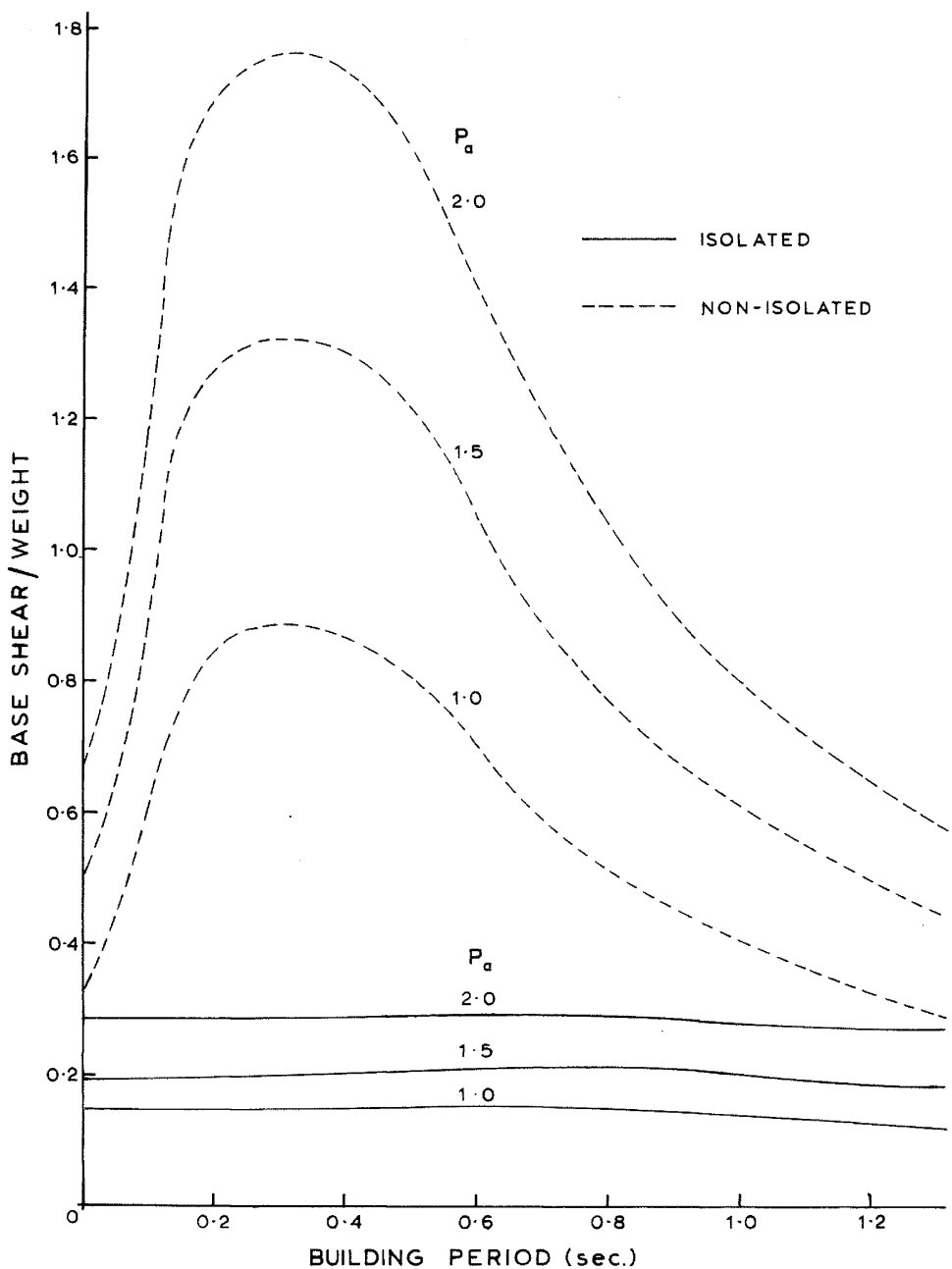

FIGURE 1: MAXIMUM BASE SHEARS FOR A SINGLE-MASS LINEAR RESONATOR, WITH AND WITHOUT BASE ISOLATION, WHEN SUBJECTED TO P TIMES THE ACCELERATIONS RECORDED AT EL CENTRO, 1940, N S.

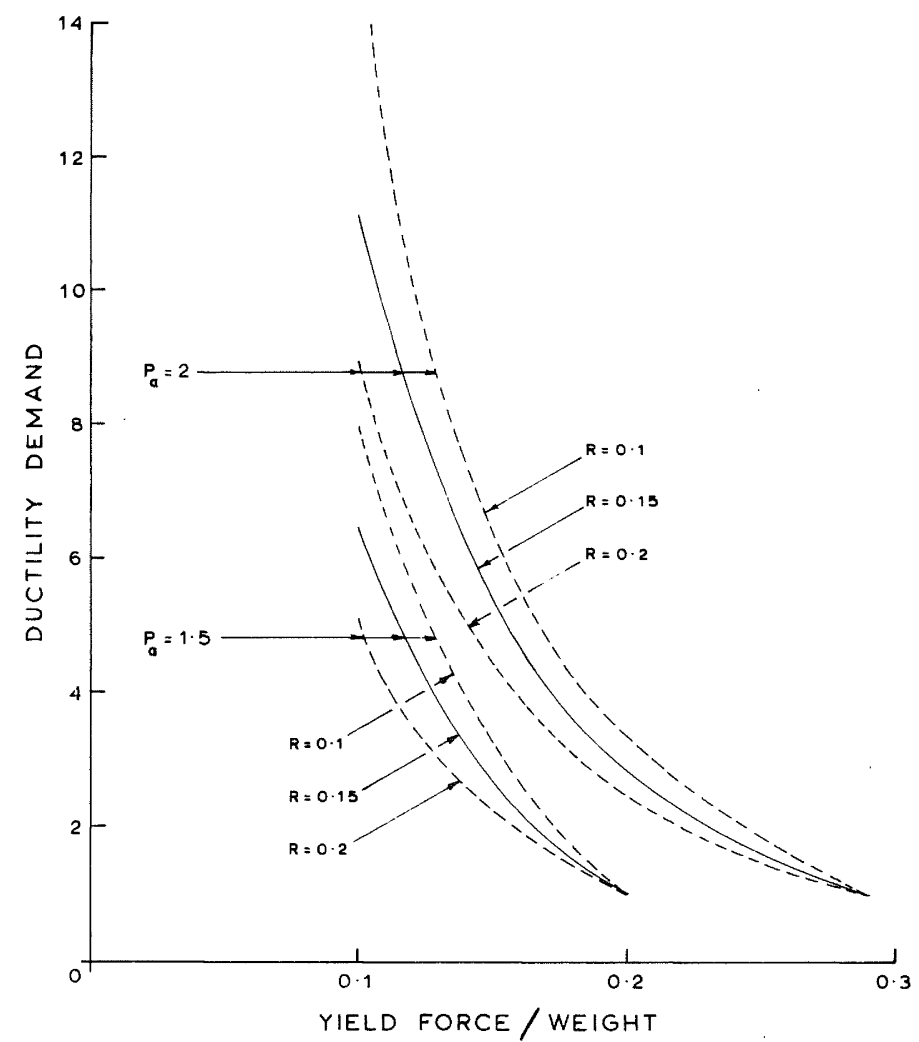

FIGURE 2: SINGLE-MASS SYSTEM WITH BILINEAR HYSTERETIC SUPPORTS, YIELD FORCE Fy , STIFFNESS RATIO R, ELASTIC PERIOD 0.35 SEC, DAMPING 0.05. BASE ISOLATED AND SUBJECTED TO $\mathrm{P}_{a}$ TIMES THE ACCELERATIONS RECORDED A T EL CENTRO, 1940, N S. 


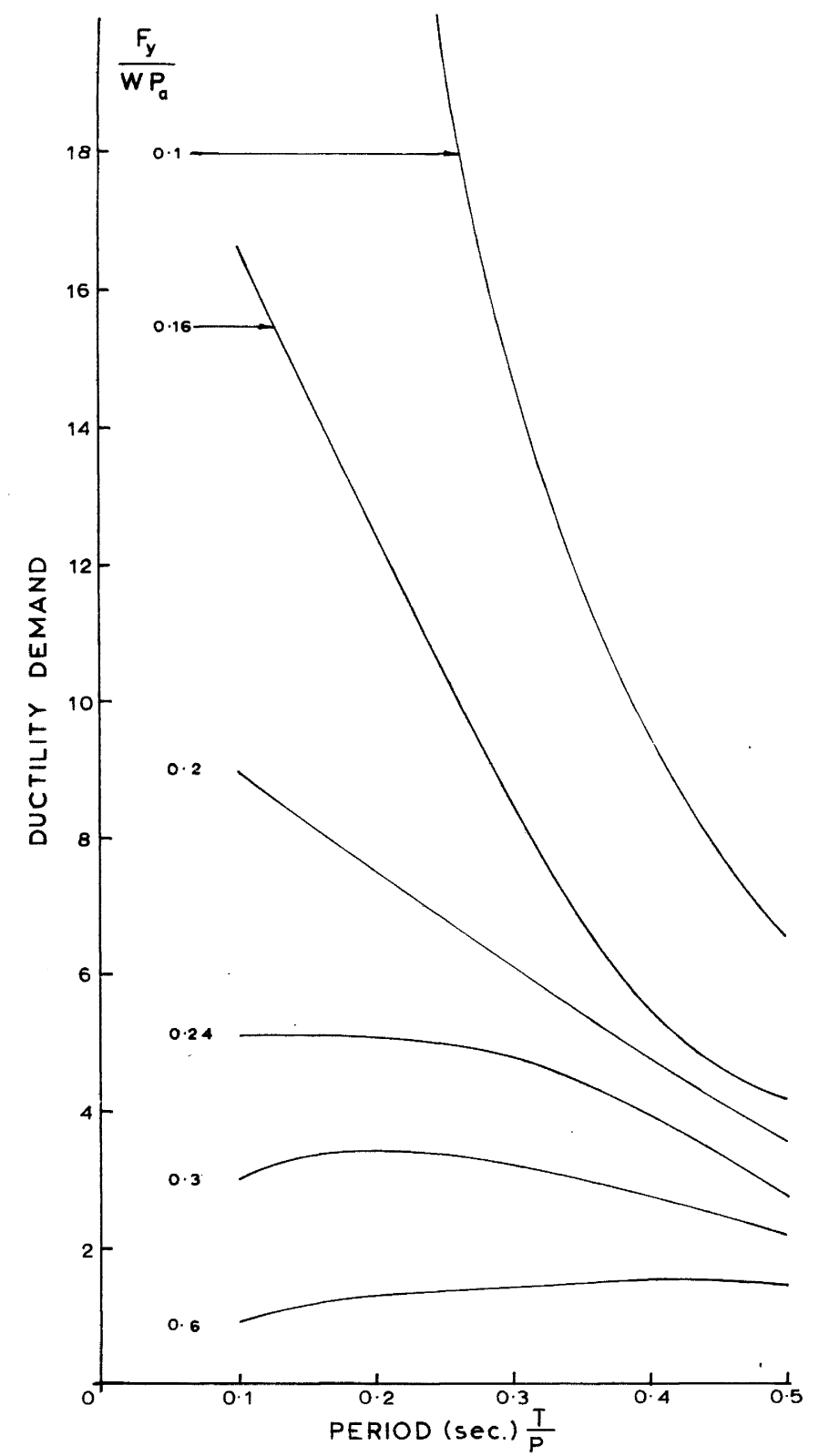

FIGURE 3: SINGLE-MASS SYSTEM WITH BILINEAR SUPPORTS, YIELD FORCE $F_{Y}$ STIFFNESS RATIO R, ELASTIC PERIOD T, DAMPING 0.05. NON-ISOLATED AND SUBJECTED TO THE EL CENTRO, 1940, N S EARTHQUAKE WITH ACCELERATIONS MULTIPLIED BY $P_{a}$ AND PERIODS MULTIPLIED BY $P_{p}$

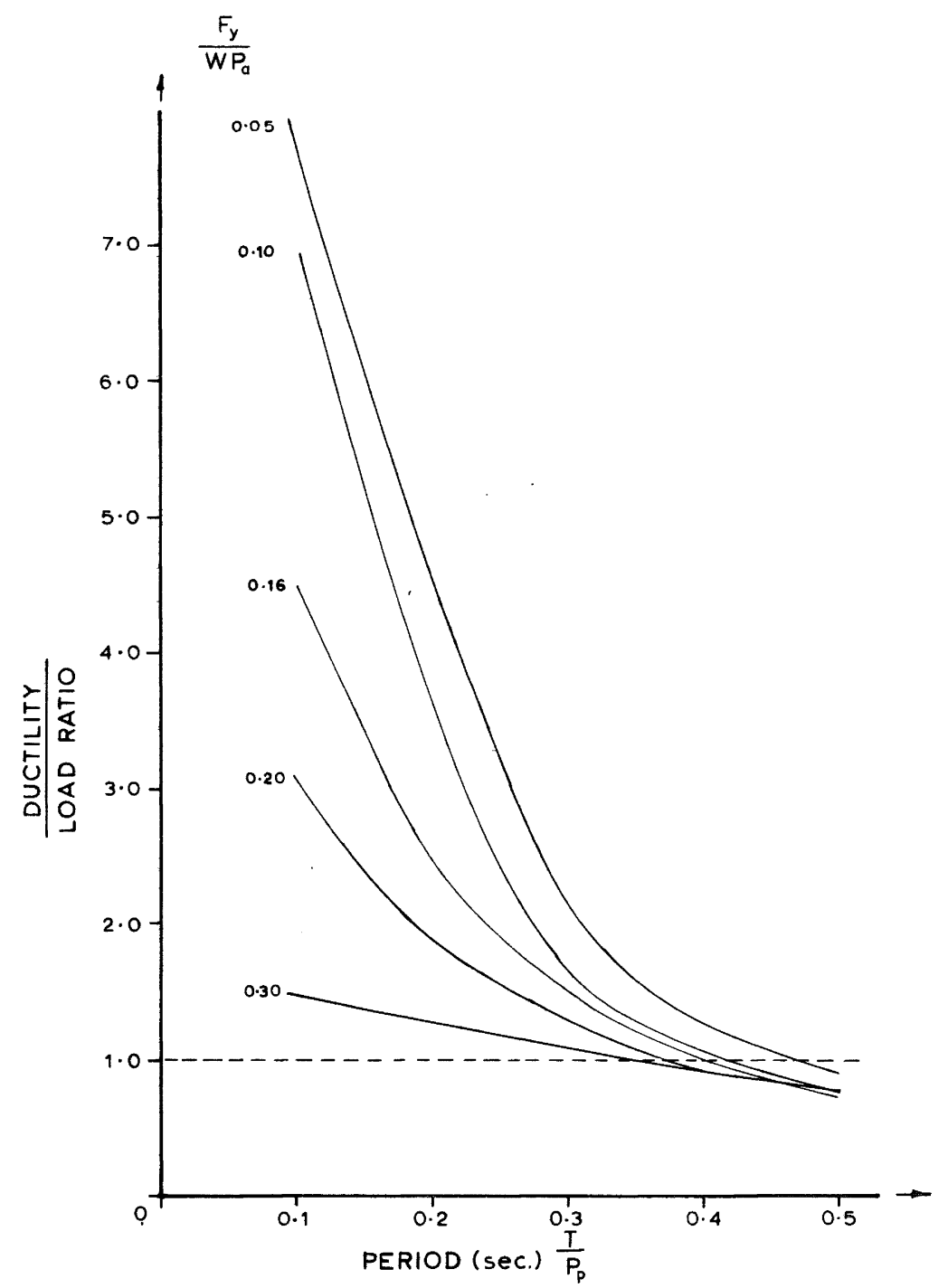

FIGURE 4: RATIO OF DUCTILITY TO LOAD RATIO FOR THE NON-ISOLATED BUILDINGS OF FIGS. 1 AND 2. LOAD RATIO= ELASTIC BASE SHEAR/YIELD LOAD 


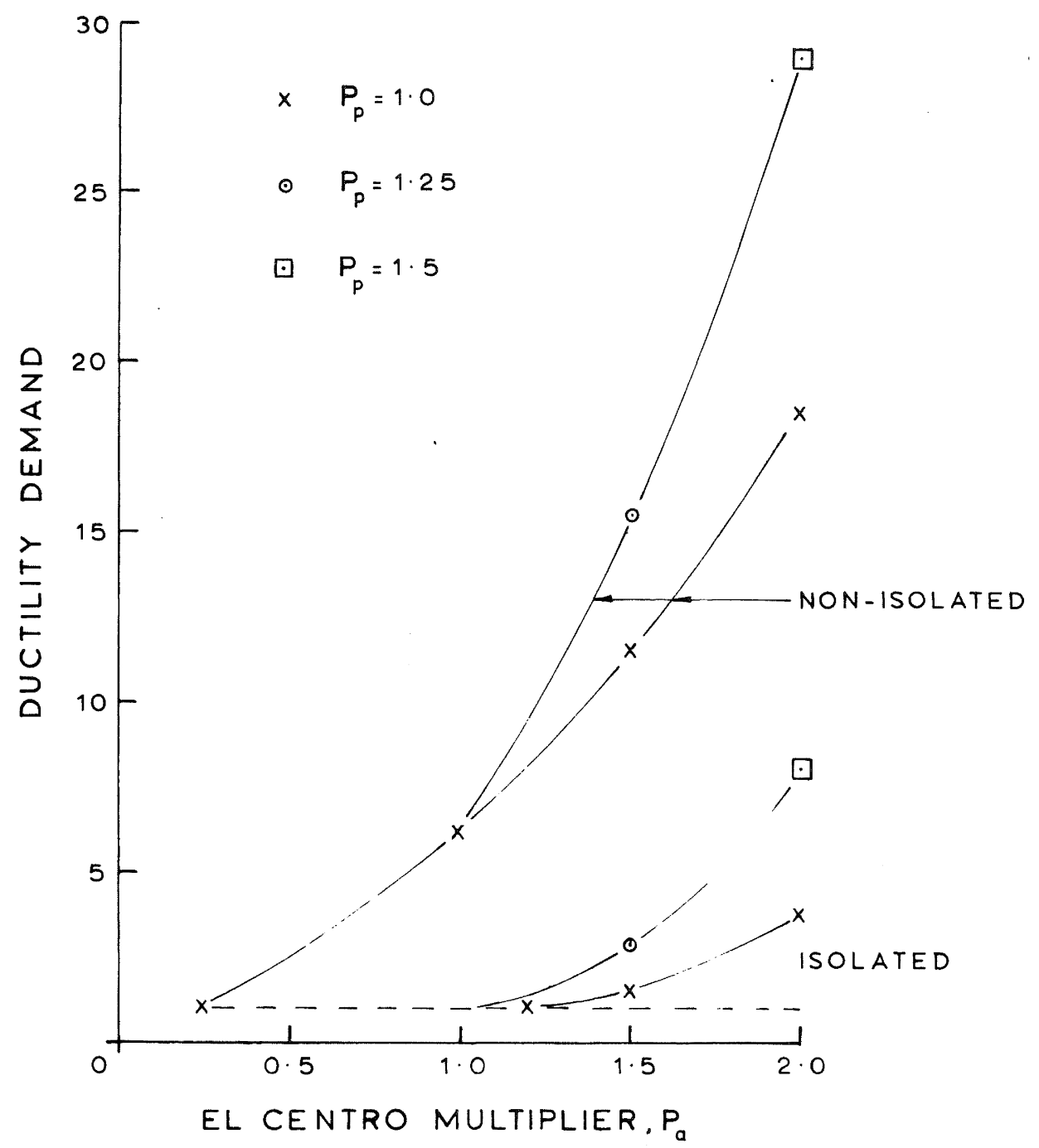

FIGURE 5: DUCTILITY DEMAND ON A BILINEAR HYSTERETIC BUILDING; PERIOD 0.25 SEC, VISCOUS DAMPING 0.05. ISOLATED; STIFFNESS RATIO 0.15, $F_{y}=0.18 \mathrm{~W}$. NON-ISOLATED; STIFFNESS RATIO 0.1, $F_{Y}=0.2 \mathrm{~W}$. EARTHQUAKE; EL CENTRO, 1940, N S, ACCELERATIONS MULTIPLIER $P_{a}$, FERIODS MULTIPLIER $P_{p}$.

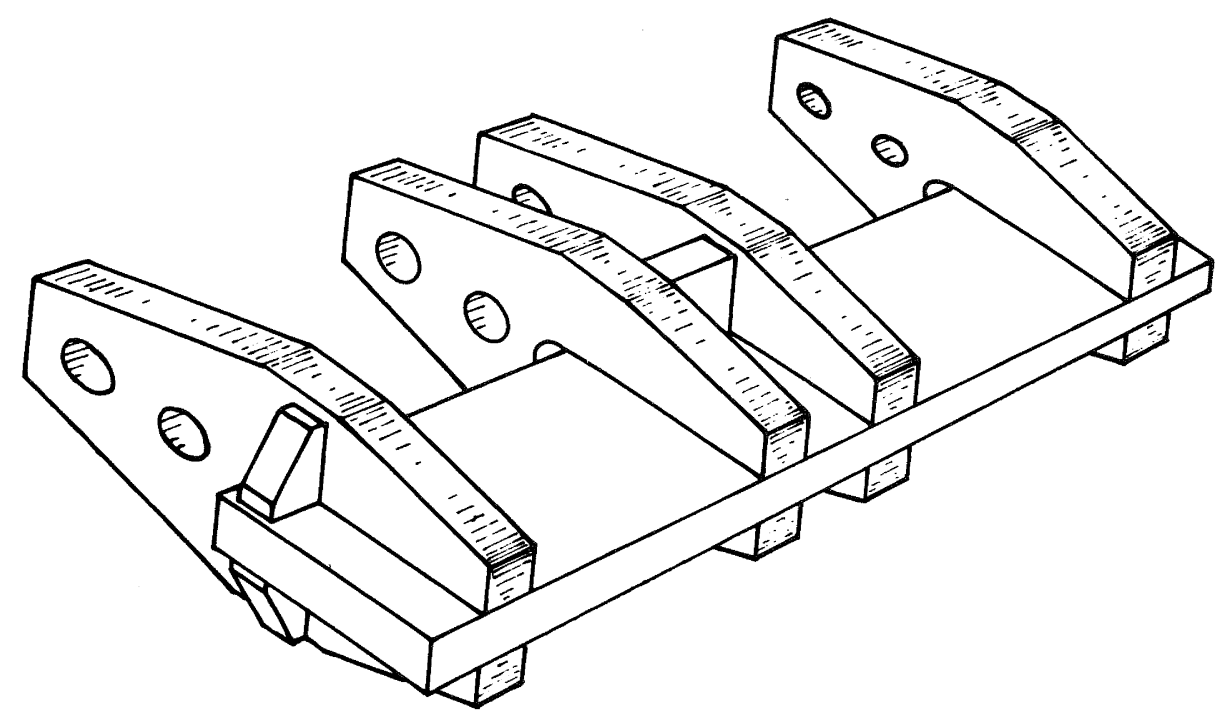

FIGURE 6: TORSIONAL-BAR HYSTERETIC DAMPER. 


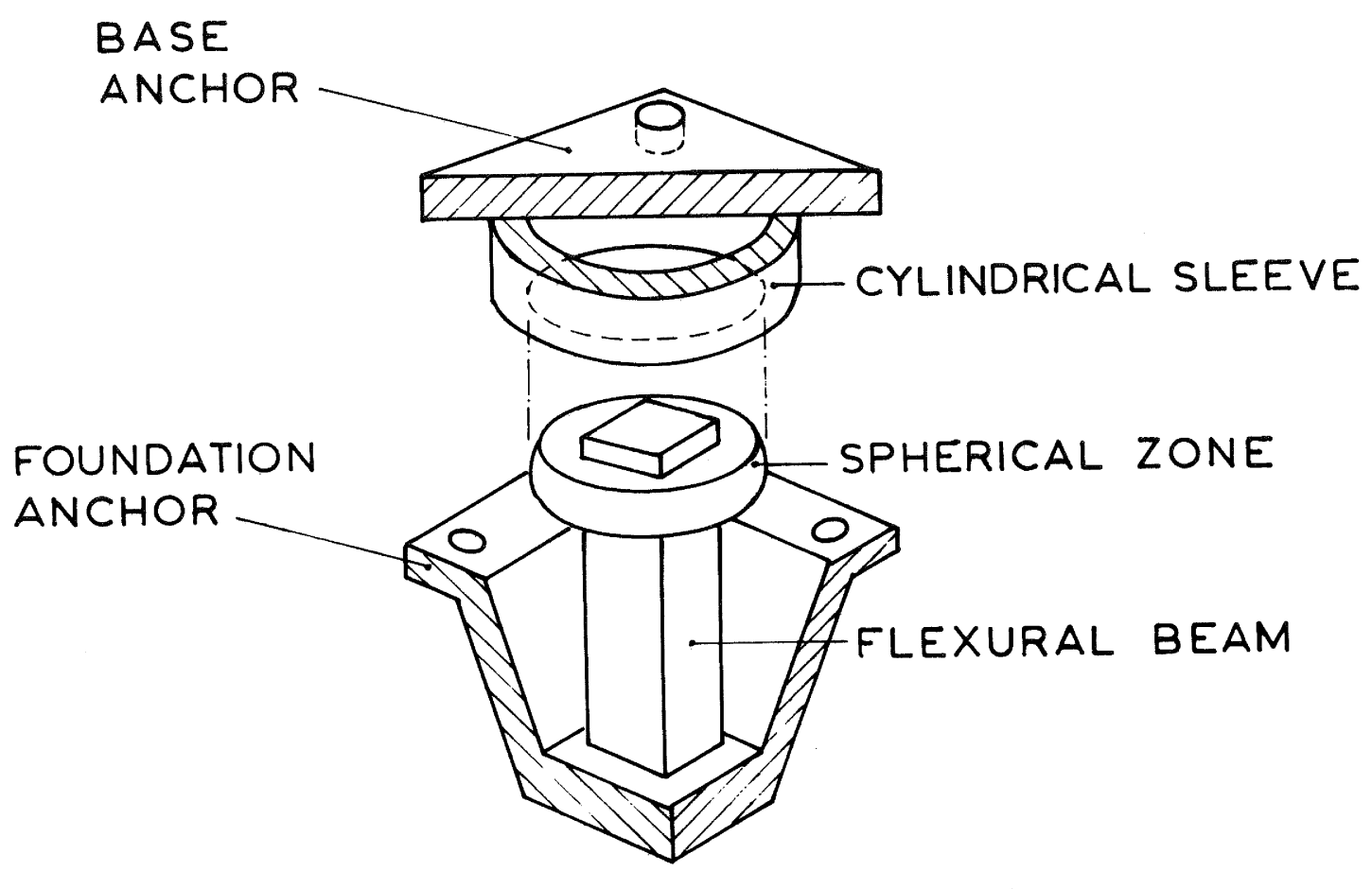

FIGURE 7: FLEXURAL-BAR HYSTERETIC DAMPER

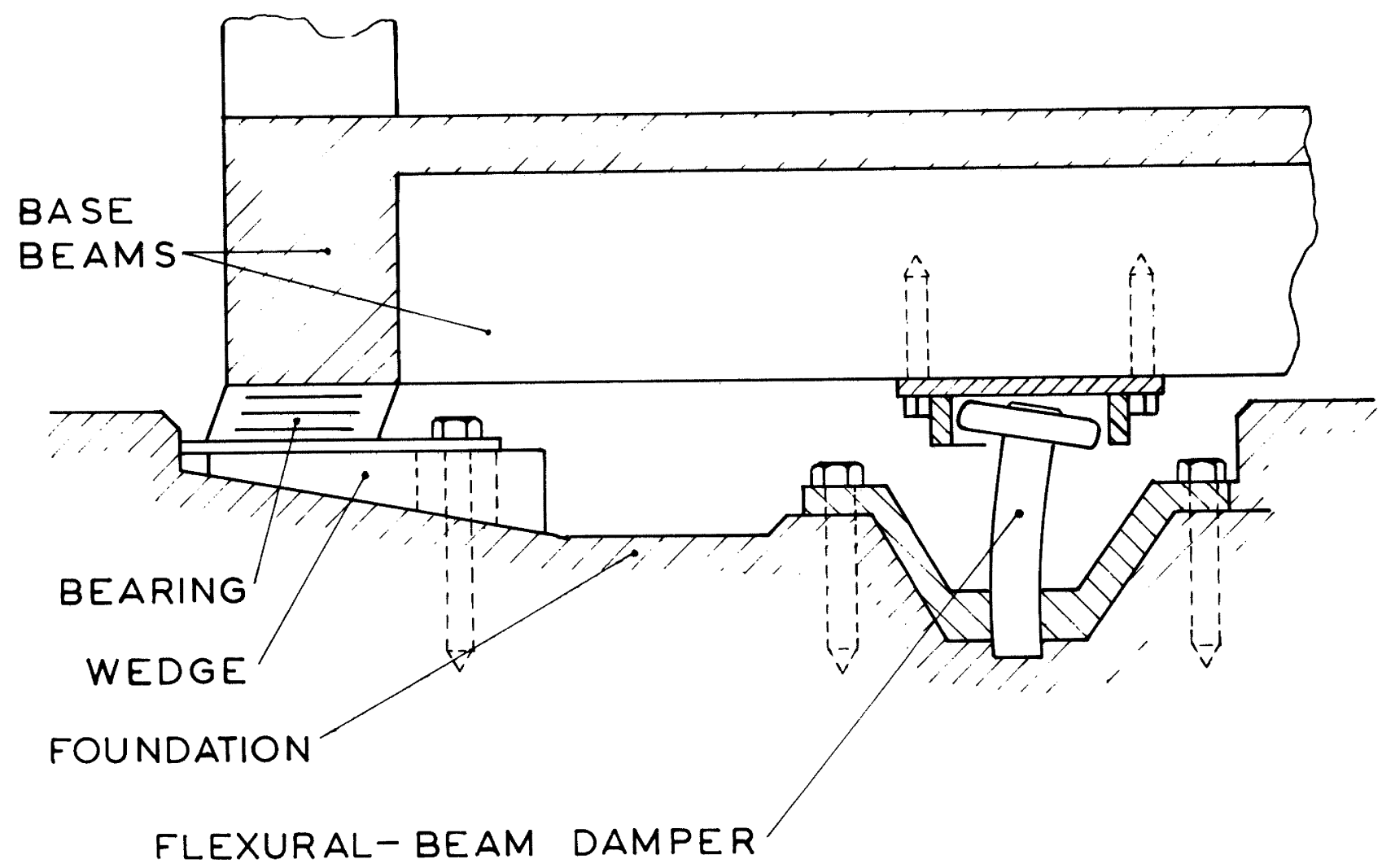

FIGURE 8: COMPONENTS OF BASE ISOLATOR USING FLEXURAL-BAR DAMPERS AND LAMINATED-RUBBER MOUNTS. 